\title{
A mesorectal incidentaloma: Rare localization of Castleman disease (Case report)
}

\author{
DANIEL ION ${ }^{1,2}$, ALEXANDRA BOLOCAN ${ }^{1,2}$, ALEXANDRU GEORGE FILIPESCU ${ }^{1,3}$, OCTAVIAN ANDRONIC ${ }^{1,2}$, \\ ANA-MARIA OPROIU ${ }^{1,4}$, ADELINA POPA $^{5}$ and DAN NICOALE PĂDURARU ${ }^{1,2}$ \\ ${ }^{1}$ General Surgery Department, 'Carol Davila' University of Medicine and Pharmacy, 050474 Bucharest; \\ ${ }^{2}$ Department of General Surgery, University Emergency Hospital of Bucharest, 050098 Bucharest; \\ ${ }^{3}$ Department of Obstetrics and Gynecology, Elias University Emergency Hospital, 011461 Bucharest; \\ ${ }^{4}$ Department of Plastic and Reconstructive Surgery, The University Emergency Hospital Bucharest, 050098 Bucharest; \\ ${ }^{5}$ Department of Dermatology, Elias University Emergency Hospital, 011461 Bucharest, Romania
}

Received May 24, 2021; Accepted June 23, 2021

DOI: $10.3892 /$ etm.2022.11194

\begin{abstract}
Incidentalomas are defined as tumors or pseudo-tumoral masses accidentally discovered during clinical and imaging investigations. We present a 51-year-old female patient who presented at the gynecology service for genital bleeding caused by uterine fibromatosis. Computerized pelvic tomography showed an engorged uterus completely deformed by numerous intramural and submucosal nodular structures suggestive of multiple fibroids. Behind the uterus, a well-defined, iodophilic, 49/51 mm diameter, tissue-shaped, nodular mass was identified, with pushing borders into the adjacent fat and showing a mass effect on the rectum against which it retained a demarcation zone. A conclusion of the histopathological examination was made. Histopathological aspects and immunohistochemical tests supported the diagnosis of Castleman disease (CD) variant vascular hyaline variant. The mesorectum is a particularly and extremely rare localization for CD, and preoperative diagnosis is difficult to achieve. The correct surgical attitude in the case of an incidental finding in this localization is the extensive resection that satisfies the presumption of a neoplastic formation.
\end{abstract}

\section{Introduction}

Incidentalomas are defined as tumors or pseudo-tumoral masses accidentally discovered during clinical and imaging investigations. Incidentalomas can exhibit a wide range of

Correspondence to: Dr Alexandra Bolocan, General Surgery Department, 'Carol Davila' University of Medicine and Pharmacy, 169 Splaiul Independentei Street, 050474 Bucharest, Romania E-mail: bolocan.alexa@gmail.com

Key words: Castleman disease, incidentaloma, mesorectum, mesorectal tumor, fibromatosis unusual morphologies such as inflammatory pseudotumors, benign or malignant neoplasms or even ectopic tissue (1-3).

In patients over 60 years of age undergoing computed tomography (CT) examination, over $7 \%$ of cases reveal incidentalomas. Among those, adrenal adenomas are the most common (4-6). In the abdominal-pelvic region, incidentalomas involve most frequently the liver, kidney and lumbosacral region (7).

Once detected using imaging techniques, questions regarding the nature and evolution of this mass with or without treatment, as well as the opportunity for surgical resection and the relationship between risk and benefit must be answered.

Incidentalomas are usually diagnosed after a CT investigation and are quite common, especially nowadays when such investigations are universally available. For example, in Canada, approximately 12.6 CTs per 100 inhabitants were performed in 2012, double compared to 2002 (8). It is easy to understand that a great proportion of these patients had some form of incidental findings during CT. A study in Greece identified incidentalomas in 138 out of 478 patients investigated by CT over a period of 6 months. Among those, only 24 patients presented with clinically significant incidentalomas (9).

When dealing with such lesions, the surgical attitude usually moves between two options: i) Undertreatment or ii) overtreatment, especially when there are no guidelines or absolute criteria for one decision or the other.

Castleman's disease (CD) was first described in 1956 in a number of individuals asymptomatic or with minimal symptoms but with a large volume of mediastinal lymph node (10). $\mathrm{CD}$ is a rare disease with an incidence of approximately 2.3/100,000 individuals (11). In 1972, a study by Keller et al classified CD into two types: i) Vascular hyaline and ii) plasma cell (12). Subsequently three histological types were defined: hyaline-vascular, plasma cell, and mixed, as well as two clinical types: unicentric and multicenter (13).

The most frequent localization is the mediastinal one, but other extrathoracic localizations with a much lower incidence have been described $(12,13)$. Usually, CD is multicentric, but 
in about $25 \%$ of cases it is unicentric $(14,15)$. CD diagnosis is often incidental, the symptoms being minimal or missing in the case of unicentric CDs (16), but for a definitive diagnosis a histologic examination is needed (17). Recently, a proposal for diagnostic criteria and classification have been made by Japanese researchers (18).

The treatment of CD includes a multimodal approach including surgery, irradiation, corticosteroids, chemotherapy and molecular therapy (19-21). The prognosis of CD is extremely good if a total excision is performed, with a 10 -year overall survival of more than $95 \%(22,23)$.

\section{Case presentation}

We present a 51-year-old female patient with essential hypertension and type II diabetes which presented at the gynecology service of the Emergency University Hospital of Bucharest (Bucharest, Romania) for genital bleeding caused by uterine fibromatosis. Bioptic and hemostatic curettage excluded endometrial neoplasia, and the Pap smear test excluded cervical neoplasia.

Computerized pelvic tomography showed an engorged uterus with transaxial dimensions of $89 \mathrm{~mm}$ by $77 \mathrm{~mm}$, and 100-mm cranio-caudal diameter, completely deformed by numerous intramural and submucosal nodular structures suggestive of multiple fibroids. The ovary and annexes were normal. Behind the uterus, a well-defined, iodophilic, 49/51 mm diameter, tissue-shaped, nodular mass was identified, with pushing borders into the adjacent fat and showing a mass effect on the rectum against which it retained a demarcation zone. In addition, multiple paraaortic and mesorectal lymphadenopathies were identified, the largest one being $15 \mathrm{~mm}$ in size.

At this point, the patient underwent an emergency surgical intervention at the same clinic, followed by histopathological examination. A median subabdominal laparotomy was practiced and total hysterectomy with bilateral anexectomy was performed. Intraoperative exploration revealed a palpable round, smooth and mobile tumor mass in the mesorectum with moderate compression on the rectum. Next, an anterior rectal resection was performed with partial excision of the mesorectum, followed by restoration of the transit through a low colorectal anastomosis with temporary protective ileostomy. At the same time, the hypogastric nerves and lower hypogastric plexus were identified and preserved.

Histological examination of the uterine portion showed the appearance of uterine leiomyoma. Histological examination of the mesorectal tumor showed a fragment presenting histopathological aspect of lymphoid tissue with small follicle, the interfollicular stroma with numerous sclerotic capillary blood vessels.

Frozen examination raised the suspicion of angioimmunoblastic lymphoma. Initially the mass appeared to be a simple case of lymphoma originating from the mesorectum. Yet, upon gross examination, the large mesorectal mass resembled a well-circumscribed gastrointestinal stromal tumor (GIST) or a peculiarly enlarged lymph node. The cut sections had a chestnut-gray color with few hemorrhagic areas. Specimen samples were fixed with $10 \%$ buffered formalin and were processed by conventional histopathological methods using paraffin embedding, sectioning and hematoxylin and eosin (H\&E) staining. Histopathological examination confirmed the initial diagnosis of lymphoma as there was no monoclonal proliferation noted after ancillary testing. Moreover, the suspicion of Castleman disease was raised based on the presence of abnormal vascularity and regression of germinal centers.

Immunohistochemical analysis found: L26/CD20 positivity in lymphoid follicles; CD3 positivity in blood vessels; CD23 positivity in lymphoid follicles; CD38 positivity in plasma from the interphilic stroma; $\kappa$ positivity in plasmocytes; $\lambda$ positivity in plasmocytes. In conclusion, the histopathological features and immunohistochemical tests supported the diagnosis of CD vascular hyaline variant.

Postoperative follow-up of the patient was uneventful and after 8 weeks the ileostoma was reversed, with complete resumption of the digestive transit.

\section{Discussion}

The increasing incidence of 'incidental' imaging findings in individuals is due to the better resolution of imaging investigations.

Once discovered, such a tumor mass raises the issue of its nature and its evolutionary potential. The indication for surgical resection should always be judged based on the risk-benefit equation, taking into account both local and general factors.

In the present case, laparotomy was mandatory due to the uterine pathology, and the decision for the incidentaloma excision was taken intraoperatively. Not knowing the histological nature of tumor tissue and its evolutionary potential, we made the decision to do an anterior rectal resection and colorectal anastomosis, being well acquainted with the technique of tumor rectal pathology.

In the case of common localizations, there is a relatively well-defined behavior in the case of incidentalomas, Yet, in this case, due to the extremely rare location, the decision for surgical resection was challenging considering the diagnostic and prognostic uncertainty.

Localization of CD in the mesorectum has been reported in only two cases in the literature $(24,25)$. Even if this localization is extremely rare and may be asymptomatic (26), CD should be included in the discussion regarding the differential diagnosis of a mesorectal tumor (27-29).

Resection in this case was guided by the principles of total rectal excision of mesorectum from rectal cancer described by Heald in 1982; namely penetration into the so-called holy plane between the fascia recti and the pelvic fascia, making an extra-fascial excision (30).

In conclusion, the mesorectum is a particularly and extremely rare localization for $\mathrm{CD}$, and preoperative diagnosis is extremely difficult to achieve. The correct surgical attitude in the case of an incidental finding in this localization is the extensive resection that satisfies the presumption of a neoplastic formation.

\section{Acknowledgements}

Not applicable. 


\section{Funding}

No funding was received.

\section{Availability of data and materials}

All the data are available in the text of the article.

\section{Authors' contributions}

All the authors were involved in conceiving and designing the present study. DI designed, drafted and wrote the manuscript. $\mathrm{DI}, \mathrm{AB}$ and $\mathrm{OA}$ were responsible for collecting and analyzing the patient data. DNP designed, drafted the manuscript and revised it critically for important intellectual content. All authors read and approved the final version of the manuscript for publication.

\section{Ethics approval and consent to participate}

We certify that the procedures and the experiments undertaken in the present study respect the ethical standards of the Helsinki Declaration of 1975, as revised in 2000, as well as the national Romanian law.

\section{Patient consent for publication}

The patient provided written informed consent for the publication of her case.

\section{Competing interests}

The authors declare that they have no competing interests.

\section{References}

1. O'Sullivan JW, Muntinga T, Grigg S and Ioannidis JPA: Prevalence and outcomes of incidental imaging findings: Umbrella review. BMJ 361: k2387, 2018.

2. Poiană C, Chiriţă C, Carşote M, Hortopan D, Ioachim D, Corneci CM and Stănescu B: Adrenal and pituitary incidentalomas in a case of Cushing's syndrome. Chirurgia (Bucur) 108: 886-891, 2013.

3. Gheorghisan-Galateanu AA, Carsote $M$ and Valea A: Incidentaloma: From general practice to specific endocrine frame. J Pak Med Assoc 67: 917-922, 2017.

4. Booth TC: Incidental findings on imaging. BMJ 361: k2611, 2018

5. Lumbreras B, Donat L and Hernández-Aguado I: Incidental findings in imaging diagnostic tests: A systematic review. Br J Radiol 83: 276-289, 2010.

6. Canadian Institute for Health Information (CIHI): Medical Imaging in Canada. CIHI, Ottawa, ON, 2013. https://www.cihi.ca/en/ access-data-and-reports. Accessed June 21, 2021.

7. Iliesiu A, Ungureanu IA, Petca A, Constantin MM, Petca RC, Sandru F, Constantin T and Dumitrascu MC: Paraganglioma presenting as a mesenteric cystic mass: A case report. Exp Ther Med 20: 2489-2492, 2020.

8. Gheorghiu ML, Hortopan D, Dumitrascu A, Caragheorgheopol A, Stefanescu A, Trifanescu R, Niculescu DA, Baciu I, Carsote M, Poiana C, et al: Age-related endocrine tumors: Non-functioning adrenal tumors as compared to pituitary adenomas. Acta Endo (Buc) 5: 371-384, 2009.
9. Soultati A, Alexopoulou A, Dourakis SP, Dimopoulou H, Katsaounis P, Cokkinos D and Archimandritis AJ: The burden of incidental findings in clinical practice in a tertiary care center. Eur J Intern Med 21: 123-126, 2010.

10. Castleman B, Iverson L and Menendez VP: Localized mediastinal lymphnode hyperplasia resembling thymoma. Cancer 9: 822-830, 1956.

11. Simpson D: Epidemiology of Castleman disease. Hematol Oncol Clin North Am 32: 1-10, 2018.

12. Keller AR, Hochholzer L and Castleman B: Hyaline-vascular and plasma-cell types of giant lymph node hyperplasia of the mediastinum and other locations. Cancer 29: 670-683, 1972.

13. Soumerai JD, Sohani AR and Abramson JS: Diagnosis and management of Castleman disease. Cancer Contr 21: 266-278, 2014.

14. Munshi N, Mehra M, van de Velde H, Desai A, Potluri R and Vermeulen J: Use of a claims database to characterize and estimate the incidence rate for Castleman disease. Leuk Lymphoma 56: 1252-1260, 2015.

15. Talat N, Belgaumkar AP and Schulte KM: Surgery in Castleman's disease: A systematic review of 404 published cases. Ann Surg 255: 677-684, 2012.

16. Szalat R and Munshi NC: Diagnosis of Castleman disease. Hematol Oncol Clin North Am 32: 53-64, 2018.

17. Wong RSM: Unicentric Castleman disease. Hematol Oncol Clin North Am 32: 65-73, 2018.

18. Fujimoto S, Koga T, Kawakami A, Kawabata H, Okamoto S, Mizuki M, Yano S, Ide M, Uno K, Yagi K, et al: Tentative diagnostic criteria and disease severity classification for Castleman disease: A report of the research group on Castleman disease in Japan. Mod Rheumatol 28: 161-167, 2018.

19. van Rhee F, Greenway A and Stone K: Treatment of idiopathic Castleman disease. Hematol Oncol Clin North Am 32: 89-106, 2018.

20. Nishimoto N, Kanakura Y, Aozasa K, Johkoh T, Nakamura M, Nakano S, Nakano N, Ikeda Y, Sasaki T, Nishioka K, et al: Humanized anti-interleukin- 6 receptor antibody treatment of multicentric Castleman disease. Blood 106: 2627-2632, 2005.

21. Estephan FF, Elghetany MT, Berry $M$ and Jones DV Jr: Complete remission with anti-CD20 therapy for unicentric, non-HIV-associated, hyaline-vascular type, Castleman's disease. Cancer Invest 23: 191, 2005.

22. Oksenhendler E, Boutboul D, Fajgenbaum D, Mirouse A, Fieschi C, Malphettes M, Vercellino L, Meignin V, Gérard L and Galicier L: The full spectrum of Castleman disease: 273 patients studied over 20 years. Br J Haematol 180: 206-216, 2018.

23. van Rhee F, Stone K, Szmania S, Barlogie B and Singh Z: Castleman disease in the 21st century: An update on diagnosis, assessment, and therapy. Clin Adv Hematol Oncol 8: 486-498, 2010.

24. Hwang MR, Chang HJ, Kim MJ, Seo GJ, Yoo SB, Park JW, Choi HS and Oh JH: Castleman's disease of the mesorectum: Report of a case. Surg Today 41: 271-275, 2011.

25. Yu G, Cao F, Gong H, Liu P, Sun G and Zhang W: Embolization of blood-supply artery followed by surgery for treatment of mesorectal Castleman's disease: Case report and literature review. Gastroenterol Rep (Oxf) 7: 141-145, 2019.

26. Saeed-Abdul-Rahman I and Al-Amri AM: Castleman disease. Korean J Hematol 47: 163-177, 2012.

27. Miulescu R, Balaban DV, Sandru F and Jinga M: Cutaneous manifestations in pancreatic diseases-a review. J Clin Med 9: $2611,2020$.

28. Sandru F, Carsote M, Valea A, Albu SE, Petca RC and Dumitrascu MC: Somatostatinoma: Beyond neurofibromatosis type 1 (Review). Exp Ther Med 20: 3383-3388, 2020.

29. Ristescu I, Pintilie G, Filip D, Jitca M, Fecheta R, Florescu I, Scripcariu V, Filipescu D and Grigoraş I: Perioperative anemia and transfusion in colorectal cancer patients. Chirurgia (Bucur) 114: 234-242, 2019.

30. Moran B and Heald RJ (eds): Manual of Mesorectal Total Excision. 1st edition. CRC Press, Taylor \& Francis Group, Boca Raton, FL, 2013. 